\title{
Revalidation of Acanthinozodium Denis, 1966 with description of three new species and discovery of a remarkable male palpal character (Araneae, Zodariidae)
}

\author{
Rudy JOCQUÉ ${ }^{1} \&$ Arnaud HENRARD ${ }^{2}$ \\ ${ }^{1,2}$ Royal Museum for Central Africa, B-3080 Tervuren, Belgium. \\ ${ }^{2}$ Earth and Life Institute, Biodiversity Research Center, UCL-17.07.04, Bâtiment Carnoy, \\ Croix du Sud, 5, B-1348, Louvain-la-Neuve, Belgium. \\ ${ }^{1}$ Email: rudy.jocque@africamuseum.be (corresponding author) \\ ${ }^{1}$ urn:1sid:zoobank.org:author:CF15016C-8CD1-4C9D-9021-44CA7DC7A5D5 \\ ${ }^{2}$ urn:lsid:zoobank.org:author:E1B02E6E-D91C-43FE-8D8C-CD102EFEE3B4
}

\begin{abstract}
The genus name Acanthinozodium Denis, 1966 is considered available and valid, with A. spinulosum Denis, 1966 as its type species. The genus is characterized by the presence of ventral rows of long setae on the femora, large anterior median eyes and a large, dorsal, crater-like pit on the cymbium. Zodariellum Andreeva \& Tyschenko, 1968 is removed from its synonymy and now only contains its type species Z. surprisum Andreeva \& Tyschenko, 1968. Three new Acanthinozodium species are described: $A$. crateriferum sp. nov. ( $\jmath^{\lambda}+$ ) from Ethiopia, A. sahelense sp. nov. ( $\delta^{\lambda}+$ ) from a wide range in the Sahel region and A. quercicola sp. nov. ( $\delta^{\lambda}$ ) from Morocco. The genus appears to have a large distribution in and around the Sahara. The possible function of the cymbial pit is discussed.
\end{abstract}

Keywords. Name availability, mating plug, Sahel region, Zodarion, Zodariellum.

Jocqué R. \& Henrard A. 2015. Revalidation of Acanthinozodium Denis, 1966 with description of three new species and discovery of a remarkable male palpal character (Araneae, Zodariidae). European Journal of Taxonomy 114: 1-23. http://dx.doi.org/10.5852/ejt.2015.114

\section{Introduction}

The spider family Zodariidae is fairly well analyzed and its phylogeny at genus level well resolved (Jocqué 1991; Ramirez et al. 2014). However, a few areas in the phylogeny remain to be studied. One of them is the huge genus Zodarion Walckenaer, 1826 and its closest relatives Zodariellum Andreeva \& Tyshchenko, 1968, Tropizodium Jocqué \& Churchill, 2005 and Parazodarion Ovtchinnikov, Ahmad \& Gurko, 2009. Their relationship cannot be solved with the characters that were mentioned in the original descriptions because some crucial characters, e.g. the femoral organ, were not yet known at that time. Among them, the genus Zodariellum Andreeva \& Tyshchenko, 1968 was only superficially described. It was synonymized with Acanthinozodium Denis, 1966 by Jocque (1991) but it remained doubtful whether this synonymy was well founded. 
In the present paper we address the nomenclatural problem of Acanthinozodium and reanalyze the presumed synonymy with Zodariellum on the base of classical and new morphological characters. Three new species are described.

\section{Material and methods}

Specimens were observed, drawn and measured with a WILD M 10 stereo microscope. Details of the female genitalia and male palps were observed with a Zeiss Stemi 2000 stereo microscope. Measurements and photographs of the habitus, details of mouthparts, detached male palps and female genitalia were taken with a Leica MZ16 using the LAS automontage software (ver. 3.8). The female genitalia were dissected and digested with pancreatin, then immersed in $75 \%$ ethanol.

For SEM photos, specimens were dried in Hexamethyldisilazane (36h), gold coated and examined and photographed with a JEOL 6480 LV scanning electron microscope. All types are deposited in the Royal Museum for Central Africa, Tervuren, Belgium (MRAC).

All measurements are in mm. All palp illustration are from left palps.

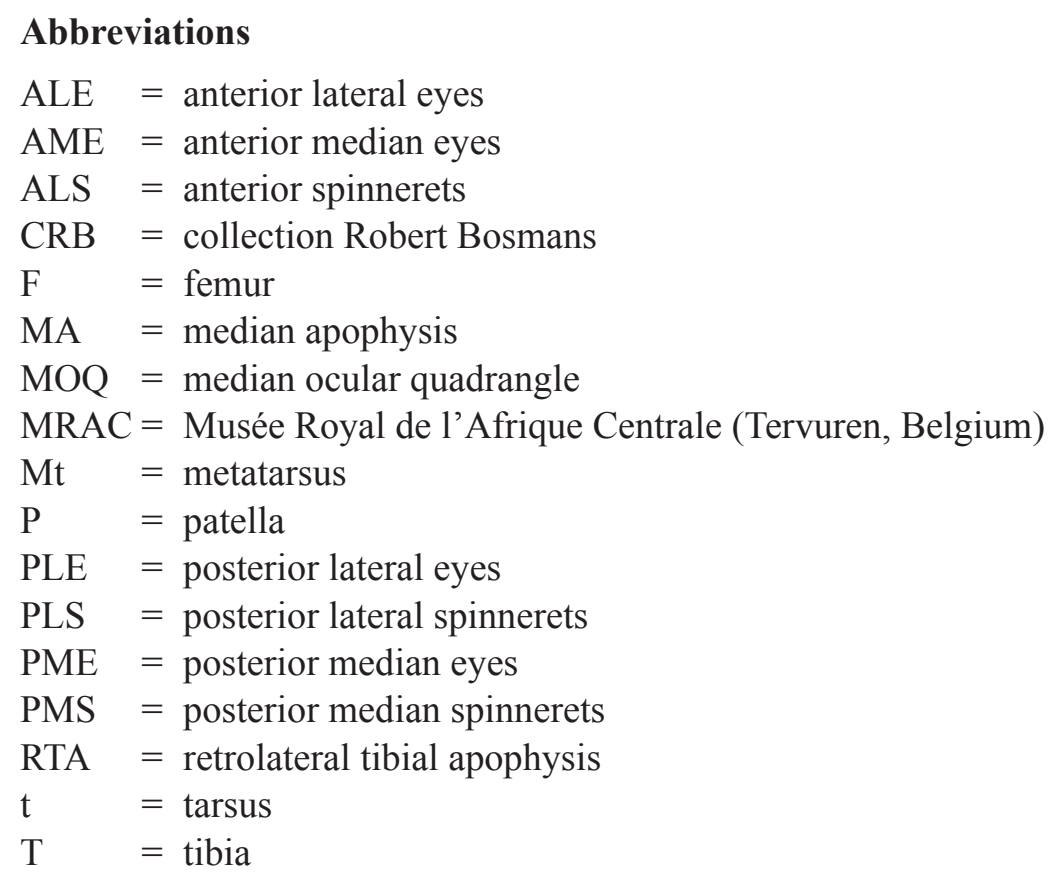

\section{Results}

Class Arachnida Cuvier, 1812

Order Araneae Clerck, 1757

Family Zodariidae Thorell, 1881

Genus Acanthinozodium Denis, 1966

\section{Diagnosis}

Members of the genus Acanthinozodium are recognized by the wide cephalothorax ( $\mathrm{L} / \mathrm{W}<1.3$ ), large AME (Fig. 4F), and all femora without flattened setae but with a double row of long ventral setae (Fig. 4C). Males are characterized by the deep dorsal pit at the base of the cymbium (Figs 9A-B, 10C, 12B-D); females by the wide epigyne with a pair of large atria and the large spermathecae with a double chamber (Fig. 9F-G). 


\section{Type species}

Acanthinozodium spinulosum Denis, 1966.

\section{Remark}

The types of $A$. spinulosum could not be traced but the description mentions two of the diagnostic characters of the genus: large AME and a double row of long ventral setae on the femora. Large AME are widely distributed among the taxa in the femoral organ clade but are important to differentiate the genus from Zodariellum that supposedly is a synonym (Jocqué 1991). The presence of dorsal spines on the femora is not diagnostic for the genus and also occurs in Zodarion nitidum (Audouin, 1826), the type species of Zodarion (Ono \& Jocqué 1986; Levy 1992).

\section{Description}

Medium size spiders $(2.8-5.7 \mathrm{~mm})$ with smooth teguments. Carapace wide $(\mathrm{L} / \mathrm{W}<1.3)$ almost hairless apart from a few longer hairs on clypeus; widest at level of coxae II-III, narrowed to about 0.68 times maximum width in males and 0.55 times maximum width in females (cephalic width measured on posterior tangent of PME). Cervical grooves poorly indicated. Profile fairly flat, often with a slight dip between eyes and fovea.

Colour. Carapace orange to shades of yellow, suffused with dark pattern; chelicerae, legs, mouthparts and sternum orange to yellow; abdomen dorsum uniform dark, venter uniform grey, darker towards sides.

EYES. In two rows: anterior row straight (eye centres), strongly procurved as seen from in front, posterior row strongly procurved. AME dark, much larger (two to four times) than remainder which are pale; AME less than half their diameter apart and as far from ALE; PME oval, three to five times their diameter apart and 1.5 to 3 times their diameter from PLE. MOQ as wide in back as in front and slightly wider than long. Clypeus convex, height about 1.5 times diameter of ALE, with some long dispersed setae.

Chilum. Absent. Chelicerae fused in the middle; intercheliceral triangle well developed; paturon dorsally covered with stout hairs; with distal cusp with one tooth; fang shorter than wide at base. Labium triangular, narrowed base. Endites roughly triangular, strongly converging. Sternum shield-shaped with rounded sides, provided with triangular extensions corresponding with coxal concavities. Slightly longer than wide.

LeGs. Slender. Formula 4123 or 4132 . Spination reduced but a few dorsal and sometimes prolateral spines on femora and ventral spines on tibiae. Femora with conspicuous double row of long ventral setae. No incised hairs on femora. Femoral organ with barbed hairs on legs I-III (Figs 9E, 12E).

FEMALE PALP. With pectinated claw turned inwards over nearly $90^{\circ}$, with distal patch of chemosensitive setae, modified prolateral, pectinated setae reduced or absent.

ABDomen. Oval; tracheal spiracle just in front of spinnerets; fairly wide, around 0.25 times maximum width of abdomen) preceded by row of modified flat setae (Figs 5F, 12E-F). Males with two spinnerets, females with six. ALS large, conical, biarticulate on common base. PLS and PMS very small. Colulus represented by haired field.

MALE PALP. Tibia with small prolateral apophysis apart from the well developed RTA. Cymbium with basolateral flange; with distal and prolateral smooth spines and dorsal patch of chemosensitive setae; prolateral modified pectinated setae reduced; base with deep crater-like pit; bulbus with hook-like median apophysis situated near distal tip; embolus flat, distal part with flange.

\section{Distribution}

Acanthinozodium is found in the semi-arid areas in and around the Sahara Desert from Senegal to Yemen. 
Acanthinozodium crateriferum sp. nov.

urn:1sid:zoobank.org:act:D55F4819-EEB4-489B-9AD5-A52FA259E42B

Figs $1-3,13$

\section{Diagnosis}

The male of this species is recognized by the shape of the RTA, which is straight and strongly tapered towards the sharp tip (Figs 2B-C, 3A-B); the female has a wide epigyne with two triangular atria divided by a thin septum (Figs 1E, 3C), very different from that of $A$. zavattarii Caporiacco, 1941 in which the atria are covered and the septum invisible from the outside.

\section{Etymology}

The name refers to the large crater-like pit at the base of the cymbium.

\section{Type material}

\section{Holotype}

ETHIOPIA: O’, Near Ras Hotel, Awash National Park, 859’ N 40¹0’ E, 29 May 1986, Russell-Smith A. (MRAC 220817).
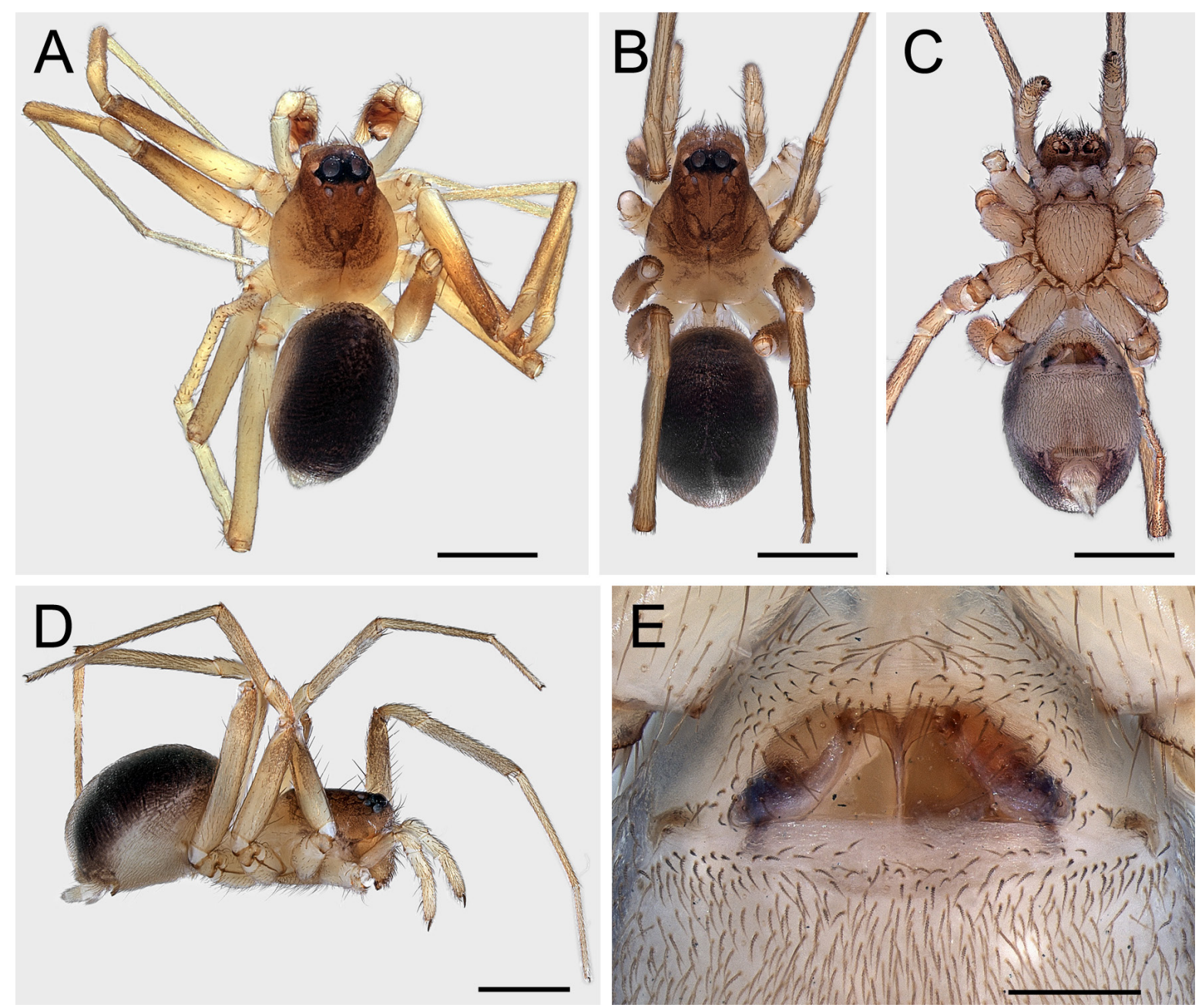

Fig. 1. Acanthinozodium crateriferum sp. nov. A. Holotype $\widehat{\jmath}$. B-E. Paratype $q$. A. Male habitus, dorsal view. B. Female habitus, dorsal view. C. Idem, ventral view. D. Idem, lateral view. E. Epigyne, ventral view. Scale bars: $\mathrm{A}-\mathrm{D}=1 \mathrm{~mm} ; \mathrm{E}=0.2 \mathrm{~mm}$. 
Paratypes

1 ऽ, 1 + , same data as holotype (MRAC 243548).

\section{Other material examined}

1 q, 1 Oct. 1986, under piles of grass, further as holotype (MRAC 220696); 1 §, 1 \%, 9 Nov. 1988, in grass and gravel, further as previous (MRAC 224602).

\section{Description}

Male

Total Length. 3.00.

CARAPACE. (Fig. 1A). 1.56 long and 1.21 wide.

Colour. (Fig. 1A). Carapace and chelicerae yellow; cephalic part with dense, brown suffusion forming butterfly pattern in front of dark red fovea; sternum and mouthparts pale yellow; legs yellow, anterior pairs with darker distal half of femora. Abdomen: Dorsum dark sepia with white spot in front of pale yellow spinnerets, the latter surrounded by ill-defined dark ring; sides turning into pale along pale cream venter.

Clypeus. 0.21 high.
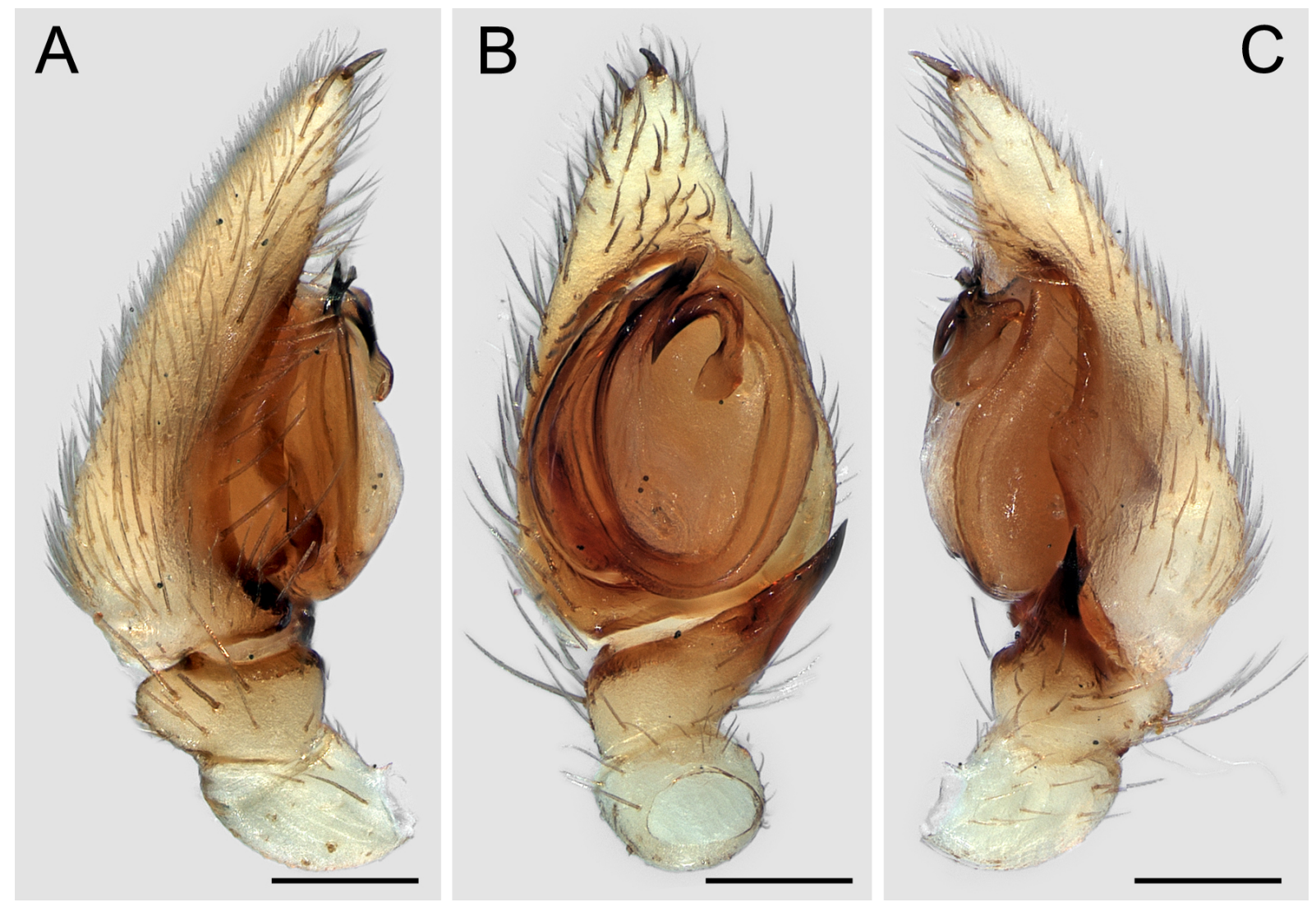

Fig. 2. Acanthinozodium crateriferum sp. nov., holotype $\widehat{\jmath}$, palp. A. Prolateral view. B. Ventral view. C. Retrolateral view. Scale bars $=0.2 \mathrm{~mm}$. 


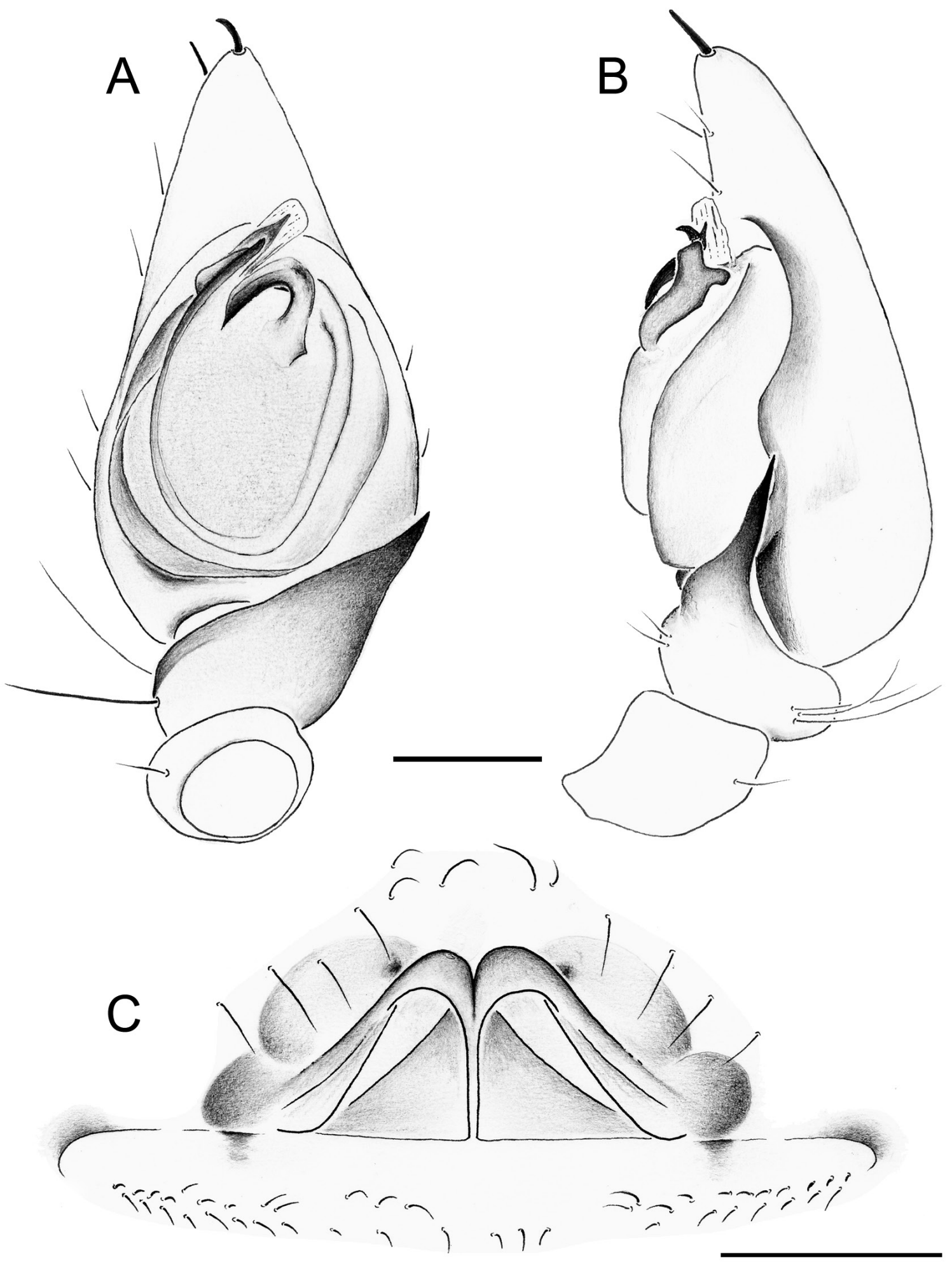

Fig. 3. Acanthinozodium crateriferum sp. nov. A-B. Holotype $\curvearrowright$. C. Paratype + . A. Male palp, ventral view. B. Idem, retrolateral view. C. Epigyne, ventral view. Scale bars $=0.2 \mathrm{~mm}$. 
EYES. AME large, round; anterior eye row straight, posterior row procurved; AME: 0.15; ALE: 0.10; PME: 0.08; PLE: 0.10; AME-AME: 0.08; AME-ALE: 0.02; PME-PME: 0.21; PME-PLE: 0.03. MOQ: width 0.39 in front, 0.34 at the back; 0.33 long.

Sternum. 0.85 long, 0.78 wide.

LEgS. Spination: all femora with two dorsal spines and two rows of long ventral setae.

ABDOMEN. With row of thin modified setae in front of spinnerets.

LEG MEASUREMENTS.

\begin{tabular}{|c|c|c|c|c|c|c|}
\hline Leg & F & P & T & Mt & t & Total \\
\hline I & 1.75 & 0.57 & 1.49 & 1.78 & 1.11 & 6.65 \\
\hline II & 1.65 & 0.57 & 1.28 & 1.63 & 0.99 & 6.10 \\
\hline III & 1.56 & 0.57 & 1.28 & 1.78 & 0.92 & 6.11 \\
\hline IV & 2.13 & 0.50 & 1.85 & 2.34 & 0.99 & 7.81 \\
\hline
\end{tabular}

PALP. (Figs 2, 3A-B). Tibia protruding dorsally; RTA straight, tapered to sharp tip; cymbium with large plug-pit just in front of tibial bulge; embolus reaching distal margin of bulbus with flat distal part; MA sickle-shaped with distal bulge; conductor rounded, membranous.

\section{Female}

TOTAL LENGTH. 3.98 .

CARAPACE. (Fig. 1B). 1.85 long and 1.42 wide.

CoLour. (Fig. 1B-D). Similar to male, but all femora distally darkened.

Clypeus. 0.25 high.

Eyes. AME: 0.16; ALE: 0.10; PME: 0.08; PLE: 0.10; AME-AME: 0.08; AME-ALE: 0.02; PME-PME: 0.23; PME-PLE: 0.03 . MOQ: width 0.44 in front, 0.38 at the back; 0.34 long.

Sternum. 0.89 long, 0.82 wide.

LEG MEASUREMENTS.

\begin{tabular}{|c|c|c|c|c|c|c|}
\hline Leg & F & P & T & Mt & t & Total \\
\hline I & 1.63 & 0.71 & 0.99 & 1.56 & 1.07 & 5.96 \\
\hline II & 1.70 & 0.64 & 1.14 & 1.49 & 0.92 & 5.89 \\
\hline III & 1.56 & 0.64 & 1.07 & 1.35 & 0.78 & 5.40 \\
\hline IV & 2.06 & 0.64 & 1.70 & 2.13 & 0.85 & 7.38 \\
\hline
\end{tabular}

Epigyne. (Figs 1E, 3C). Much wider than long; with two triangular atria divided by thin median septum; spermathecae visible in transparency along distal side of triangle.

\section{Variation}

Total length of paratype male 2.8. Carapace colour may vary from bright orange to yellowish orange.

\section{Distribution}

Known only from the type locality (Fig. 13). 


\section{Acanthinozodium sahelense sp. nov. urn:1sid:zoobank.org:act:01A0026D-5A5E-4CCD-A6CE-241708236D18}

Figs 4-9, 13

\section{Diagnosis}

The male of this species is recognized by the shape of the RTA, which is about as long as the length of the tibia, slightly curved down and dorsoventrally flattened; it has a typical large ventral bulge; extremity of the MA is slightly indented (Fig. 8A). Females are characterized by the epigyne (Figs 5G-H, 6C) in which the three sections of the frontal margin are strongly curved.

\section{Etymology}

The name refers to the wide area of distribution in the Sahel zone of western Africa.

\section{Type material}

\section{Holotype}

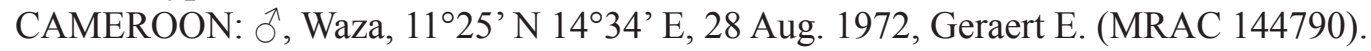
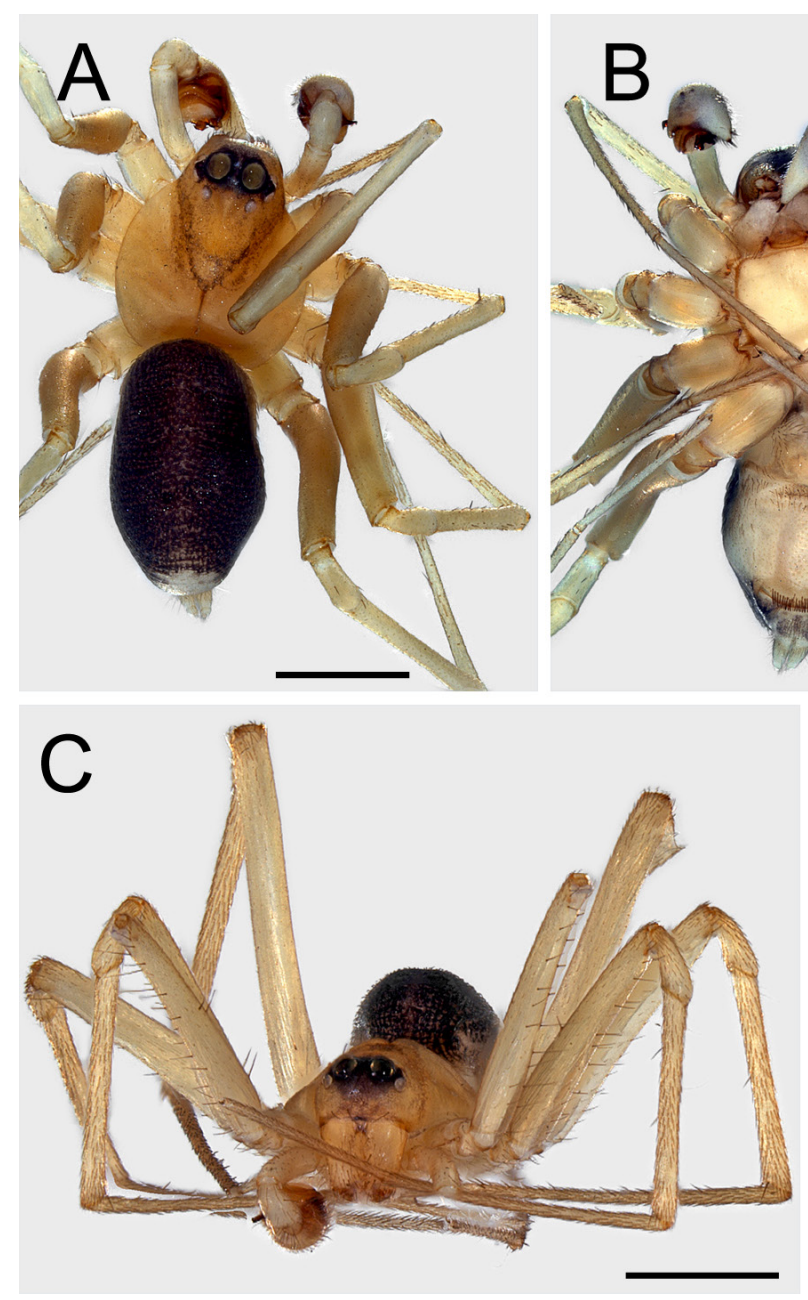
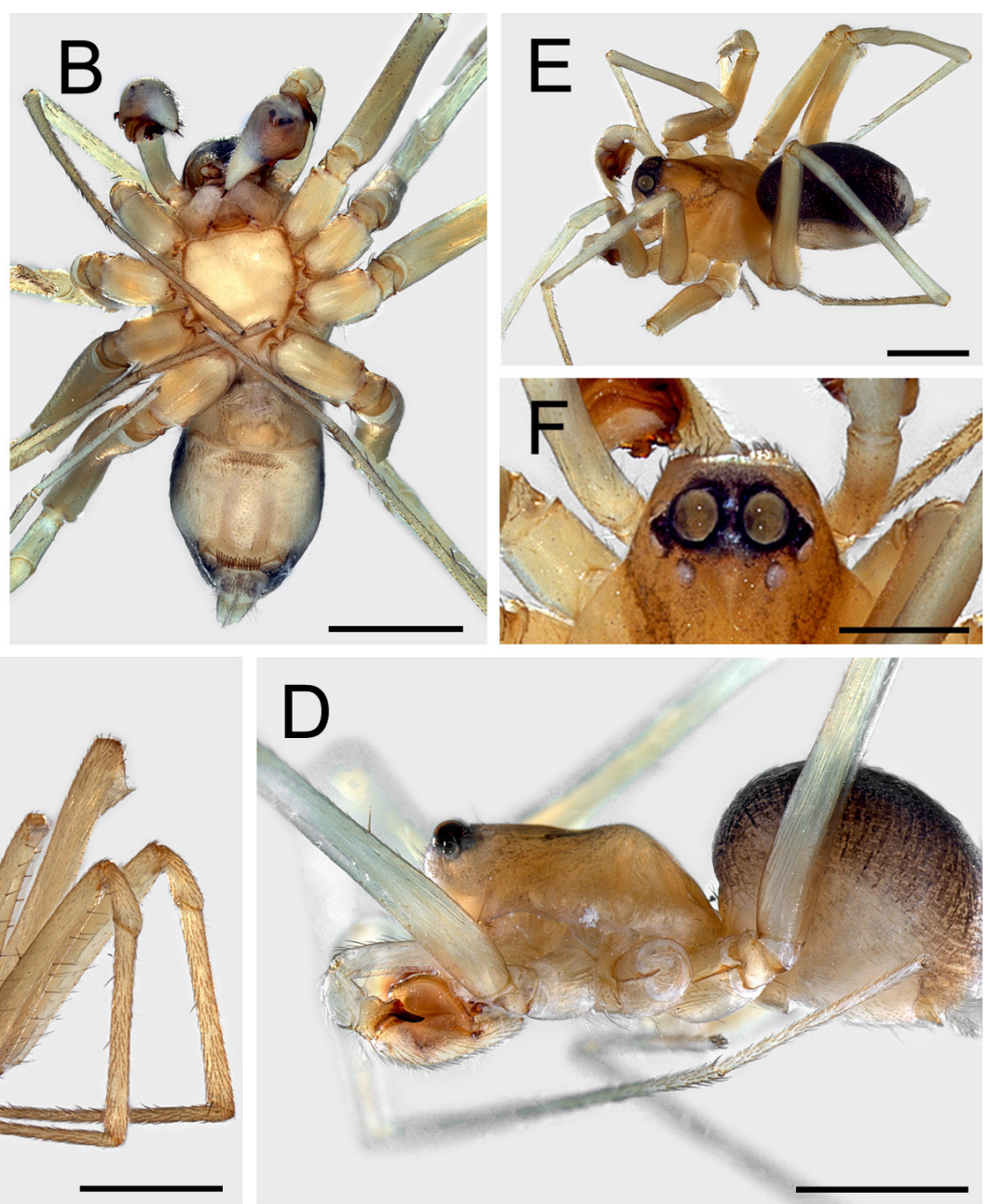

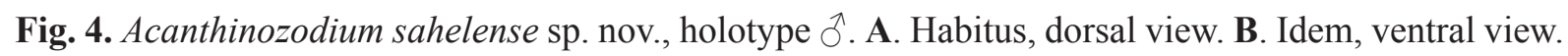
C. Idem, frontal view. D. Idem, lateral view. E. Idem, dorsolateral view. F. Carapace, eye region, dorsal view. Scale bars: $A-E=1 \mathrm{~mm} ; F=0.5 \mathrm{~mm}$. 


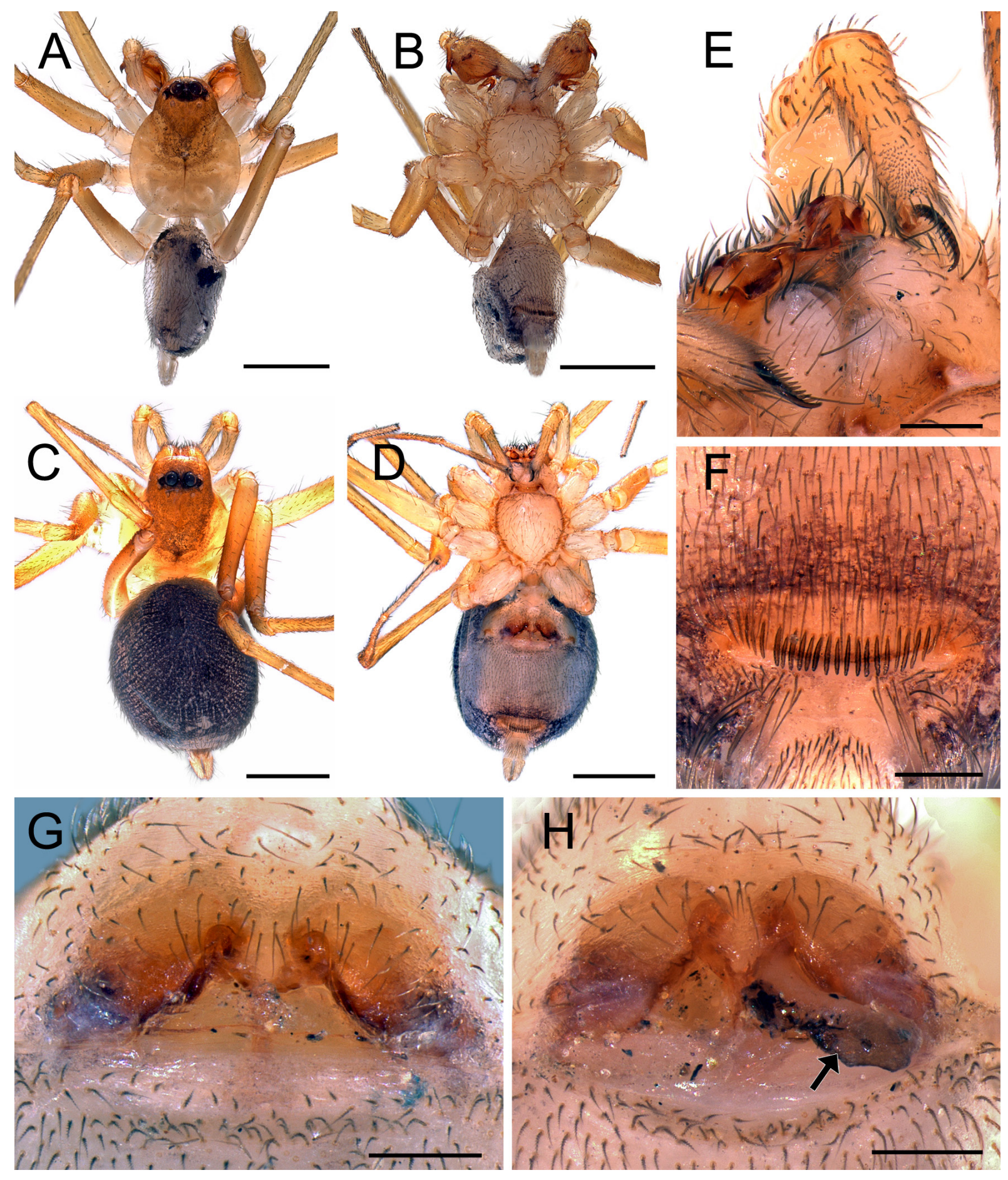

Fig. 5. Acanthinozodium sahelense sp. nov. A-B. đ from Faro Game Reserve (MRAC 221205). C-H. 우 from same sample. A. Male habitus, dorsal view. B. Idem, ventral view. C. Female habitus, dorsal view. D. Idem, ventral view. E. Female, mouthparts and palps, ventral view. F. Female, abdomen, modified setae in front of tracheal spiracle, ventral view. G. Epigyne, ventral view. H. Epigyne, other specimen; arrow indicates plug. Scale bars: $A-D=1 \mathrm{~mm} ; \mathrm{E}-\mathrm{F}=0.2 \mathrm{~mm}$. 

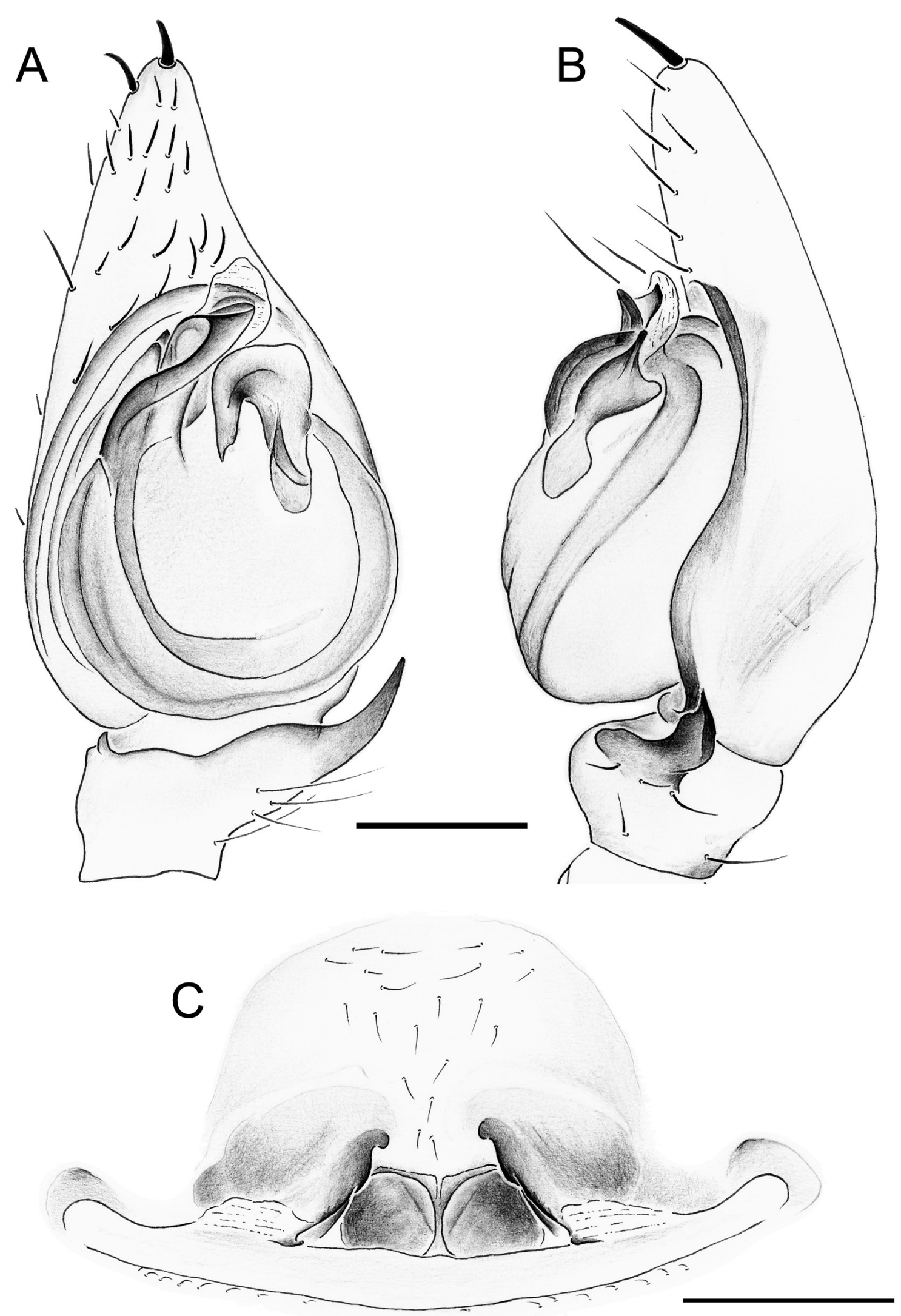

Fig. 6. Acanthinozodium sahelense sp. nov. A-B. Holotype ${ }^{\lambda}$. A. Palp, ventral view. B. Idem, retrolateral view. C. $q$ from Faro Game Reserve (MRAC 221205), epigyne, ventral view. Scale bars $=0.2 \mathrm{~mm}$. 


\section{Other material examined}

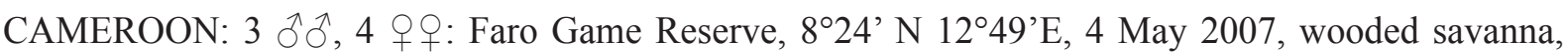
pitfall, Jocqué R., Loosveldt K., Baert L., Alderweireldt M. (MRAC 221205); 2 q : as previous, 1 May 2007 (MRAC 221147); 1 : : as previous, 5 May 2007, gallery forest, pitfall (MRAC 221183). IVORY

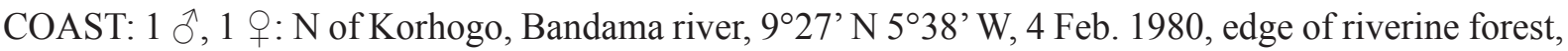

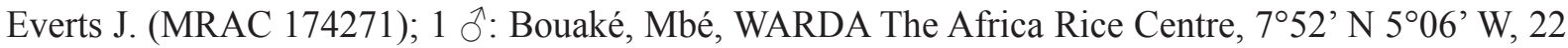
Aug. 1992, pitfall trap, hydromorphic rice, Russell-Smith A. (MRAC 235937). BURKINA FASO: 1 đ: Sissamba, 13³0' N 2²8' W, 19 Oct. 1993, pitfalls, treated C1, De Visscher M.-N. \& Balança G. (MRAC 207576). SENEGAL: 1 ㅇ: S. of Richard Toll, 16²0’ N 15³0' W, 28 Aug. 1989, pitfall, savanna, Everts J. (MRAC 170712); 1 \&: as previous, 20 Aug. 1989 (MRAC 170716); 2 $\sigma^{\lambda}$ : as previous, 2 Sep. 1989 (MRAC 170719).

\section{Description}

\section{Male}

Total LENGTH 3.55 .
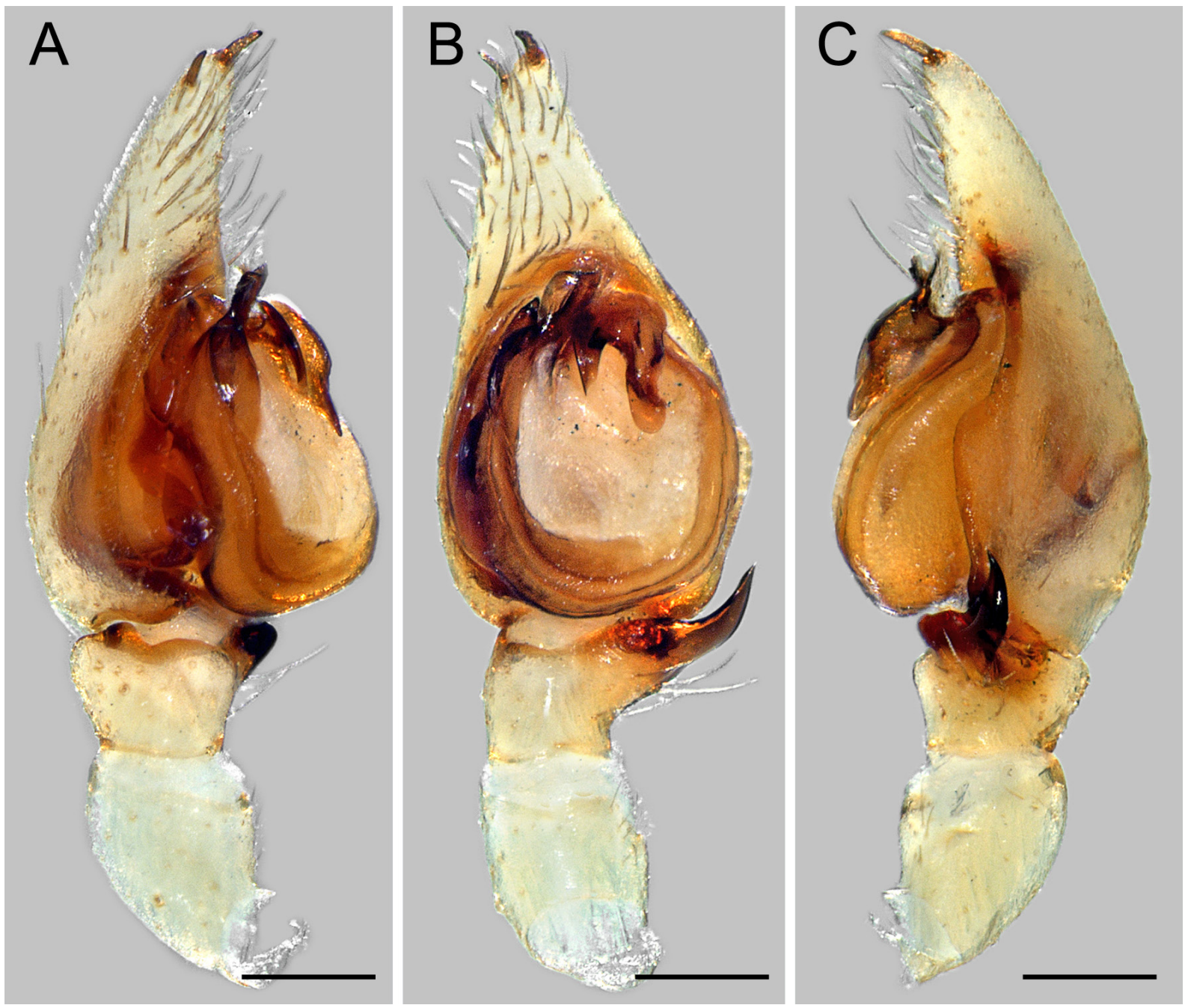

Fig. 7. Acanthinozodium sahelense sp. nov., holotype $\widehat{\jmath}$, palp. A. Prolateral view. B. Ventral view. C. Retrolateral view. Scale bars $=0.2 \mathrm{~mm}$. 
Carapace. (Figs 4A, C-E, 5A-B). 1.85 long and 1.49 wide.

Colour. (Figs 4, 5A-B). Carapace and chelicerae yellow; brown suffusion on cervical grooves; fovea dark reddish brown; sternum and mouthparts pale yellow; legs uniform yellow. Abdomen: dorsum dark sepia with large white spot in front of pale yellow spinnerets, the latter surrounded by ill-defined dark ring; sides turning into pale along pale cream venter.

Clypeus. 0.31 high.

EYES. (Fig. 4F). AME large, round; anterior eye row straight, posterior row strongly procurved; AME: 0.20; ALE: 0.10; PME: 0.10; PLE: 0.08; AME-AME: 0.10; AME-ALE: 0.03; PME-PME: 0.20; PMEPLE: 0.07. MOQ: width 0.49 in front, 0.44 at the back; 0.39 long.

Sternum. 1.42 long, 0.99 wide.

LEGS. Spination: all femora with one dorsal spine and two rows of long ventral setae.
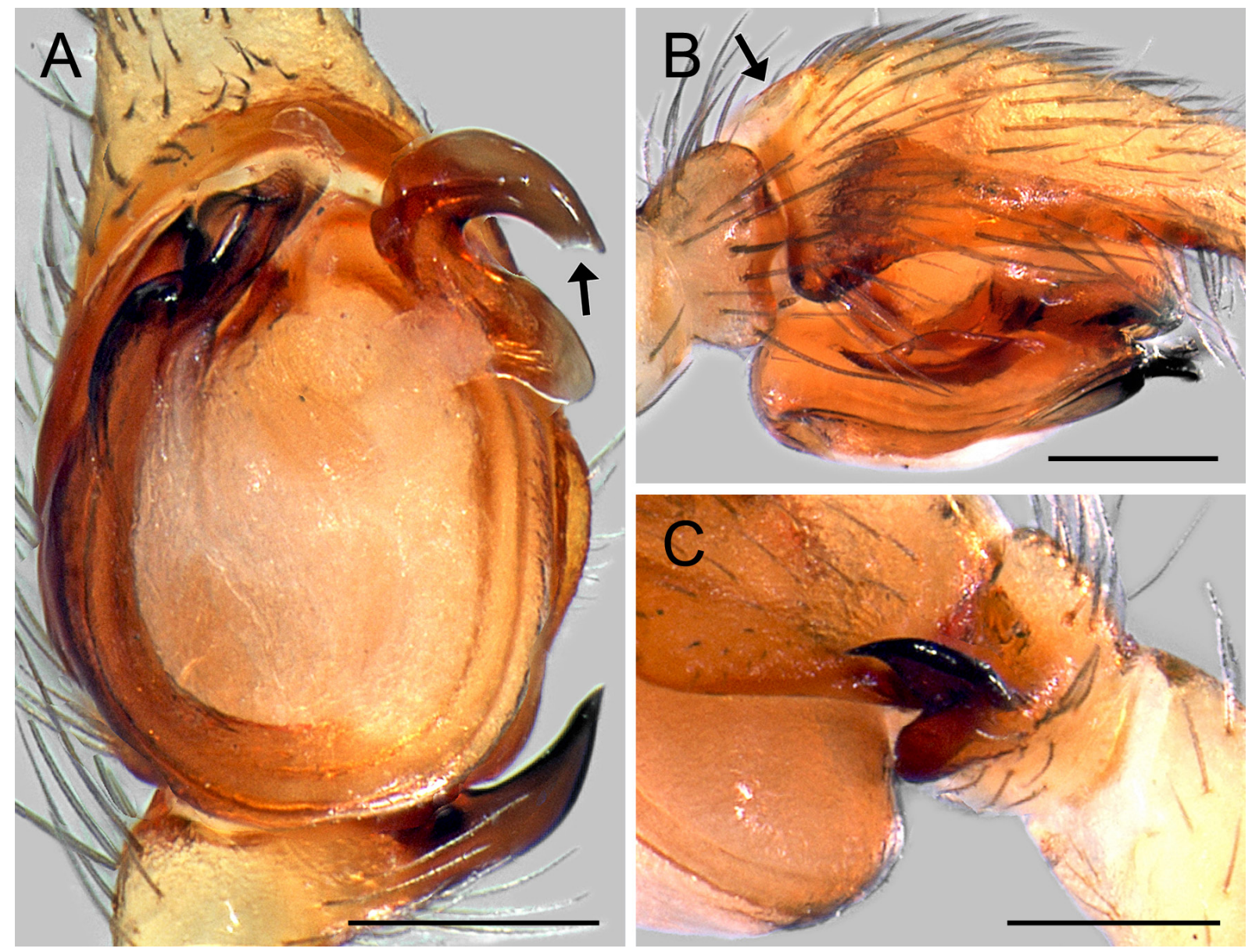

Fig. 8. Acanthinozodium sahelense sp. nov., đ from Faro Game Reserve (MRAC 221205), palp. A. Detail of bulbus with MA in expanded position, ventral view; arrow indicates the indentation of the MA tip. B. Tibia and base of bulbus, prolateral view; arrow indicates position of the crater-like plug pit. C. Retrolateral view. Scale bars $=0.2 \mathrm{~mm}$. 

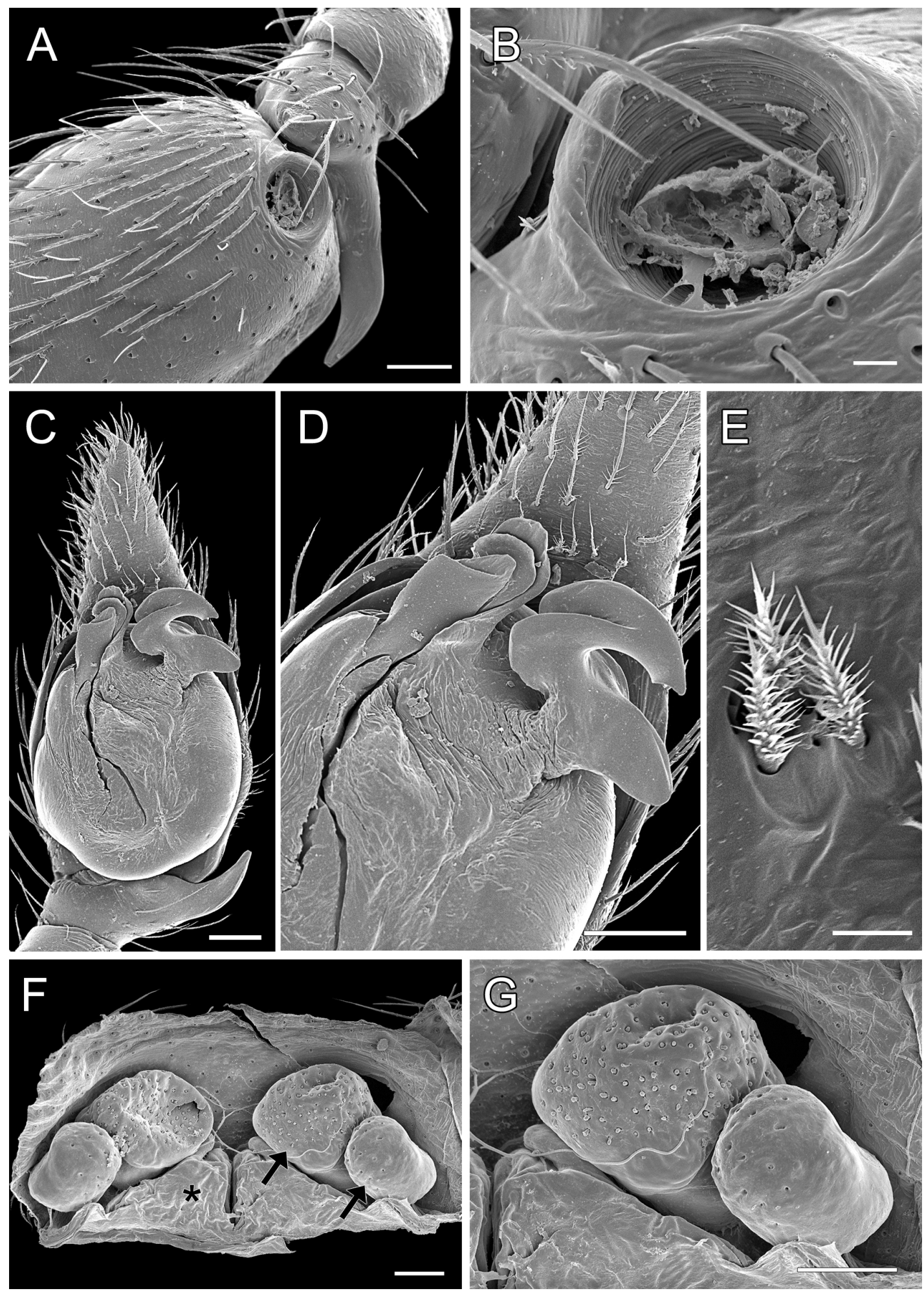

Fig. 9. Acanthinozodium sahelense sp. nov. SEM photos of $\hat{\partial}$ and $q$ from Faro Game Reserve (MRAC 221183). A. Male palp, base of cymbium, dorsal view. B. Detail of previous showing "plug pit", dorsal view. C. Male palp, ventral view. D. Detail of previous, showing MA in expanded position. E. Male, femoral organ. F. Epigyne, after digestion, dorsal view; arrows indicate the two spermatheca chambers; star indicates the atria. G. Detail of previous showing spermatheca with two chambers. Scale bars: A, $\mathrm{C}-\mathrm{D}, \mathrm{F}-\mathrm{G}=100 \mu \mathrm{m} ; \mathrm{B}, \mathrm{E}=10 \mu \mathrm{m}$. 
AвDOMEn. With row of thin modified setae in front of spinnerets.

LEG MEASUREMENTS.

\begin{tabular}{|c|c|c|c|c|c|c|}
\hline Leg & F & P & T & Mt & t & Total \\
\hline I & 2.66 & 0.63 & 2.17 & 2.10 & 1.47 & 9.03 \\
\hline II & 2.10 & 0.70 & 1.54 & 2.17 & 1.33 & 7.84 \\
\hline III & 2.03 & 0.63 & 1.40 & 2.10 & 1.26 & 7.42 \\
\hline IV & 2.10 & 0.84 & 2.17 & 2.80 & 1.96 & 9.87 \\
\hline
\end{tabular}

PALP. (Figs 6A-B, 7-8, 9A-D). Tibia protruding dorsally; RTA about as long as length of tibia, slightly curved down and dorso-ventrally flattened; with conspicuous ventral bulge; cymbium with large plugpit just in front of tibial bulge; embolus curved, flat, distal part with dorsal and ventral lamellae; MA strongly curved backward, distal extremity slightly indented; conductor rounded, membranous.

\section{Female}

Total LENGTH. 5.04.

CARAPACE. (Fig. 5C) 2.34 long and 1.85 wide.

Colour. (Fig. 5C-F). Similar to male, but cephalic area more strongly suffused with dark brown.

Clypeus. 0.26 high.

Eyes. AME: 0.20; ALE: 0.10; PME: 0.08; PLE: 0.10; AME-AME: 0.10; AME-ALE: 0.03; PME-PME: 0.33; PME-PLE: 0.08. MOQ: width 0.46 in front, 0.43 at the back; 0.39 long.

STERnum. 1.28 long, 1.07 wide.

LEG MEASUREMENTS.

\begin{tabular}{|c|c|c|c|c|c|c|}
\hline Leg & F & P & T & Mt & t & Total \\
\hline I & 2.52 & 0.70 & 2.03 & 2.80 & 1.54 & 9.59 \\
\hline II & 2.45 & 0.70 & 1.89 & 2.66 & 1.19 & 8.89 \\
\hline III & 1.68 & 0.70 & 1.82 & 2.87 & 0.98 & 8.05 \\
\hline IV & 2.94 & 0.77 & 2.52 & 2.80 & 1.19 & 10.22 \\
\hline
\end{tabular}

EpIGyNe. (Figs 5G-H, 6C). Wider than long; with two atria divided by thin median septum; anterior atria margin with three sections, one central, two lateral; all curved; spermathecae visible in transparency at extremities of central section.

\section{Variation}

Intensity of suffusion in cephalic area is variable. Total length of females varies between 3.4 and 5.1; that of males between 3.3 and 3.5.

\section{Distribution}

Very wide, from northern Cameroon in the east, to Senegal in the west (Fig. 13). 


\section{Acanthinozodium quercicola sp. nov. urn:1sid:zoobank.org:act:917D7A4F-2400-416F-8BC2-08013EB70E44}

Figs $10-11,13$

\section{Diagnosis}

The male of this species is characterized by the shape of the sinuous, by dorsolaterally flattened RTA and by the MA with dorsal bulge.

\section{Etymology}

The name refers to the habitat where the types were found: Quercus suber woodland.

\section{Material examined}

\section{Holotype}

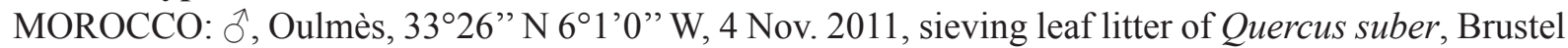
H. (MRAC 243549).

\section{Paratype}

$1 \delta^{\lambda}$ : same data as holotype (MRAC 243549).

\section{Description}

\section{Male}

Total LENGTH. 3.91.

CARAPACE. (Fig. 10A). 1.92 long and 1.49 wide.

Colour. (Fig. 10A-B). Carapace and chelicerae brownish yellow; clypeus, around eyes and cephalic area with dark brown suffusion forming butterfly pattern in front of black fovea; thoracic area with darker striae; mouthparts pale yellow; sternum yellow with dark margin; legs brownish yellow. Abdomen: dorsum dark sepia, no pale spot in front of pale cream spinnerets; sides and venter pale sepia.

Clypeus. 0.20 high.

EYES. AME large, round; anterior eye row straight, posterior row strongly procurved; AME: 0.15: ALE: 0.10; PME: 0.08; PLE: 0.08; AME-AME: 0.08; AME-ALE: 0.02; PME-PME: 0.20; PME-PLE: 0.05. MOQ: width 0.34 in front, 0.46 at the back; 0.31 long.

Sternum. 0.99 long, 0.85 wide.

LEGS. Spination: femora: I with 3 dorsal 1 prolateral, II with 2, III and IV with 1 dorsal spine; two rows of long ventral setae.

ABDOMEN. With row of modified flat setae in front of spinnerets preceded by dense cover of flattened setae.

LEG MEASUREMENTS:

\begin{tabular}{|c|c|c|c|c|c|c|}
\hline Leg & F & P & T & Mt & t & Total \\
\hline I & 1.89 & 0.70 & 1.75 & 2.03 & 1.19 & 7.56 \\
\hline II & 1.89 & 0.70 & 1.61 & 1.75 & 1.05 & 7.00 \\
\hline III & 1.61 & 0.70 & 1.26 & 1.96 & 0.84 & 6.37 \\
\hline IV & 2.24 & 0.77 & 2.10 & 2.31 & 0.91 & 8.33 \\
\hline
\end{tabular}



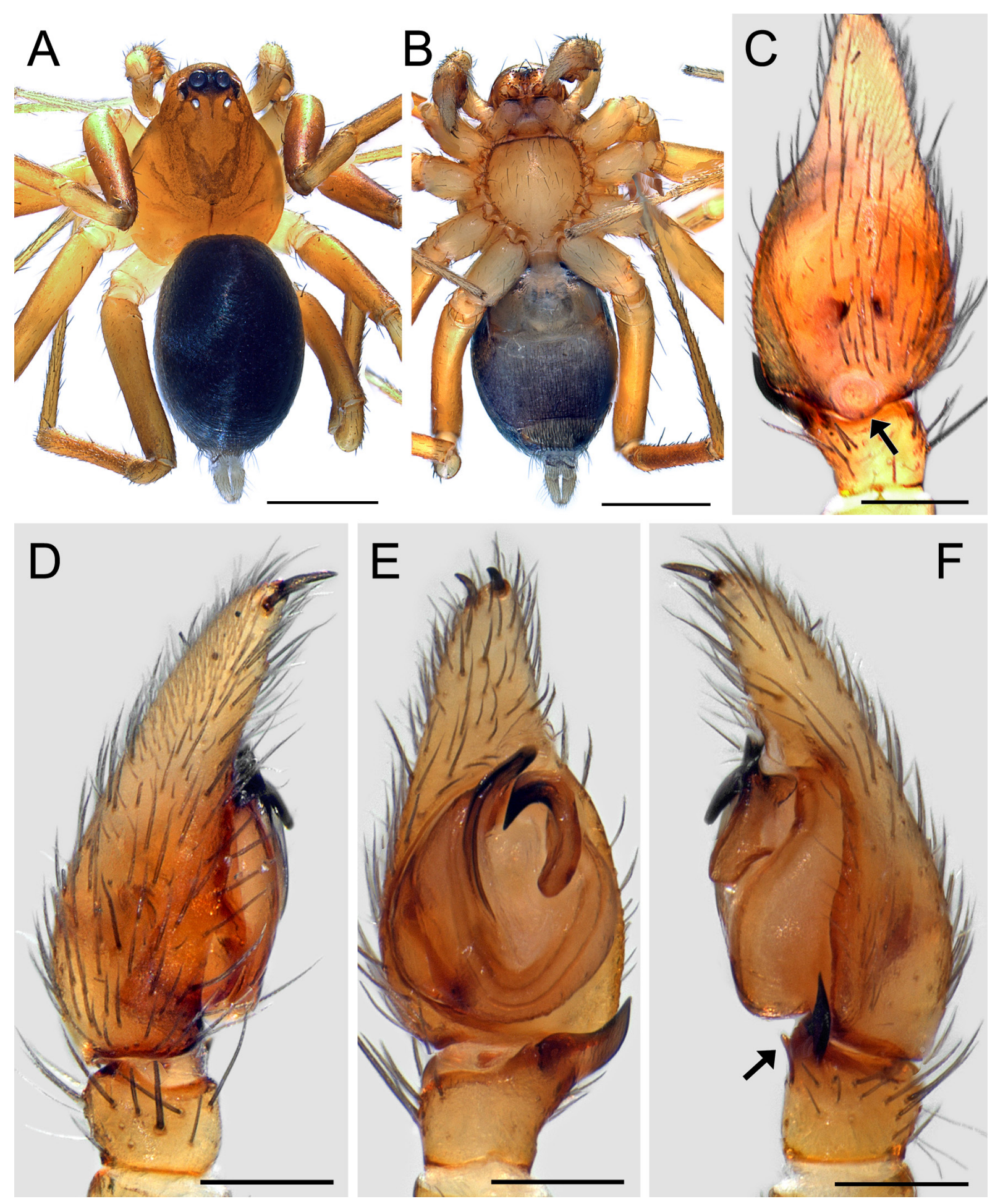

Fig. 10. Acanthinozodium quercicola sp. nov., holotype $\widehat{\partial}$. A. Habitus, dorsal view. B. Idem, ventral view. C. Palp, dorsal view; arrow indicates the crater-like plug pit. D. Idem, prolateral view. E. Idem, ventral view. F. Idem, retrolateral view; arrow indicates the tooth at base of the RTA. Scale bars: A-B = $1 \mathrm{~mm} ; \mathrm{C}-\mathrm{F}=0.2 \mathrm{~mm}$. 
PALP. (Figs 10C-F, 11). Tibia slightly produced forward dorsally; RTA short, dorsoventrally flattened, sinuous in ventral view; cymbium with dorsal plug pit in front of tibial protrusion; embolus broad at base, tapered to rounded tip with dorsal and ventral lamellae; MA fairly long, sickle shaped, with strong dorsal boss; conductor membranous, rounded.

\section{Female}

Unknown.

\section{Distribution}

Only known from the type locality in Morocco (Fig. 13).
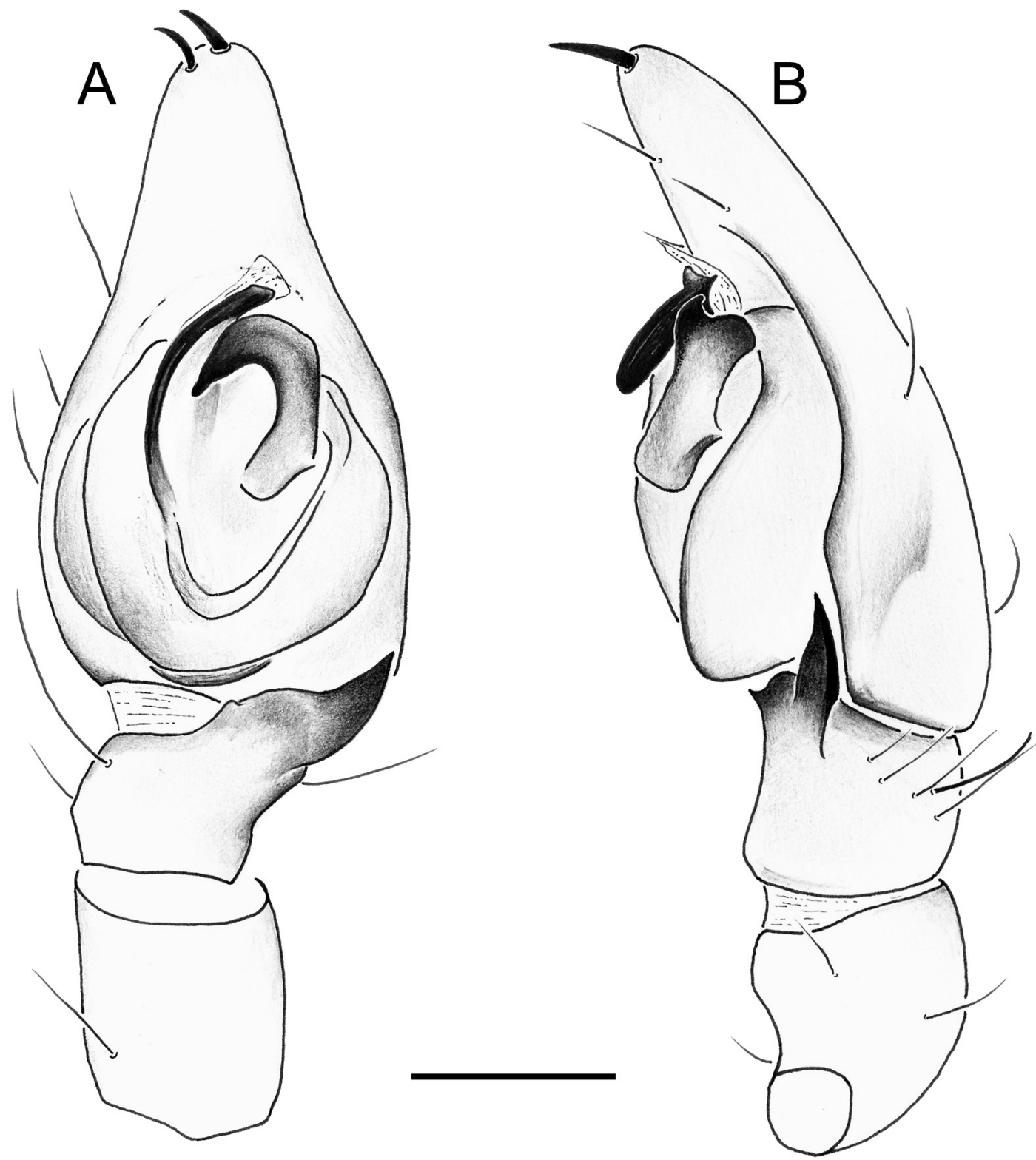

Fig. 11. Acanthinozodium quercicola sp. nov., holotype ${ }^{\lambda}$, palp. A. Ventral view. B. Retrolateral view. Scale bar $=0.2 \mathrm{~mm}$. 

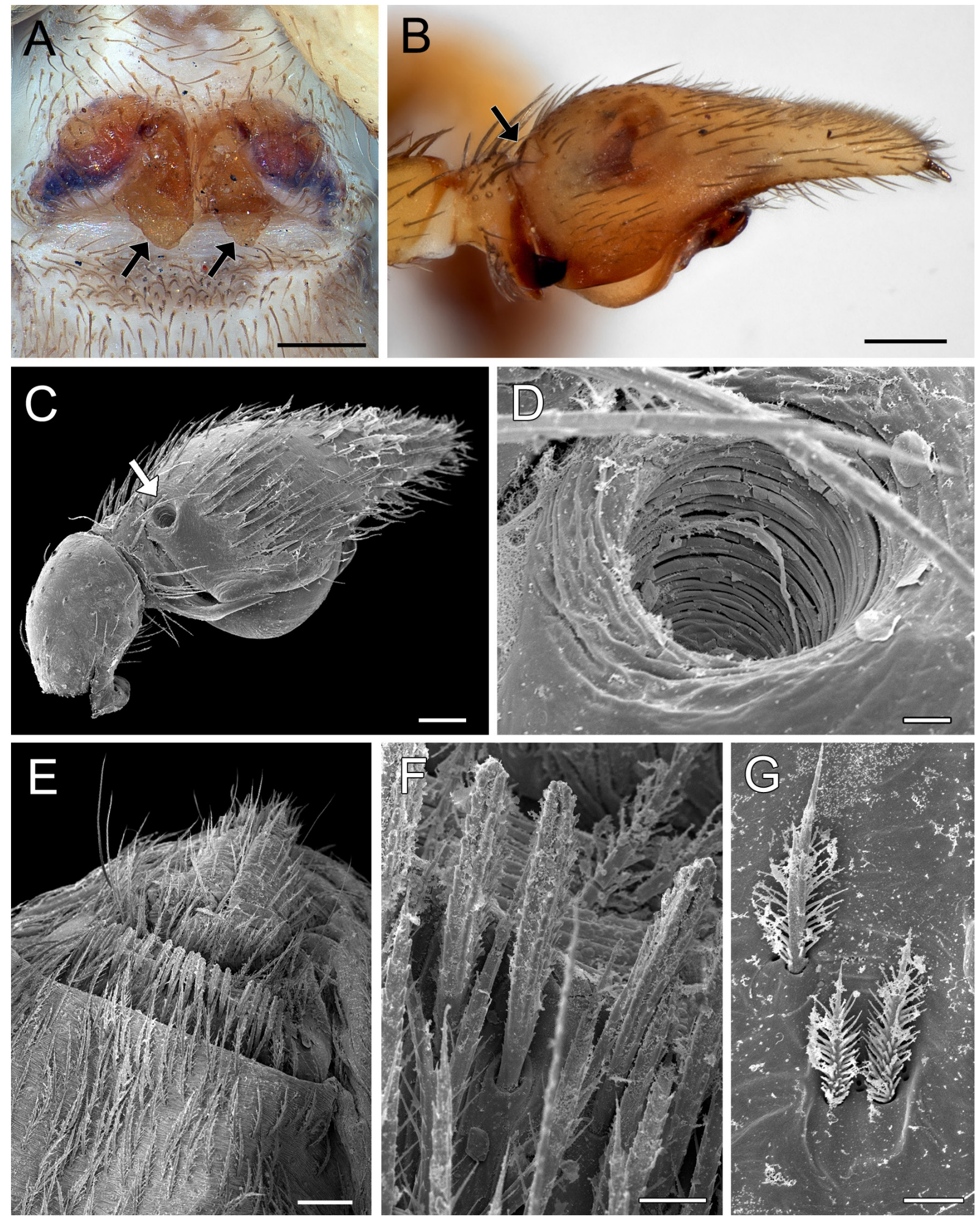

Fig. 12. A. Acanthinozodium tibesti Jocqué, 1991, holotype $q$ (MRAC 133011), epigyne, ventral view; arrows indicate both sides plugged. B. Acanthinozodium sahariense Denis, 1959 (CRB), male palp, dorsolateral view; arrow indicates the crater-like plug pit. C. Acanthinozodium sericeum Denis, 1956 (CRB), male palp, dorsolateral view; arrow shows the crater-like plug pit. D. Idem, detail of previous. E. Same specimen, abdomen, ventral view. F. Idem, detail of previous. G. Same specimen, femoral organ on leg II. Scale bars: A-B $=0.2 \mathrm{~mm} ; \mathrm{C}, \mathrm{E}=100 \mu \mathrm{m} ; \mathrm{F}=20 \mu \mathrm{m} \mathrm{D}, \mathrm{G}=10 \mu \mathrm{m}$. 


\section{Discussion}

\section{The nomenclatural problem}

In 1952 J. Denis described (in French) three species in a genus "Acanthinozodium" without designating a type species. He did not do this because the publication in which he wanted to describe the genus was greatly delayed and only appeared in 1966. In the latter paper he described Acanthinozodium spinulosum and mentioned that this should have been the type species: "Le genre Acanthinozodium est intermédiaire entre les Diores et les Zodarium: son type aurait dû être $A$. spinulosum : mais par suite du retard apporté à la publication de cette étude, j'ai été amené à en donner une description très sommaire (in the 1952 paper)" (our remark in brackets).

In his catalogue, Brignoli (1983) regarded the name Acanthinozodium as available, with the type species A. spinulosum, because the paper of Denis (1966) could be recognized as the first "revision" of the genus thereby establishing its availability. In a revision of the Zodariidae, Jocque (1991) also considered Acanthinozodium as available and valid, and designated the first species described in the 1952 paper (A. cirrisulcatum Denis, 1952) as the type species. In 2001 Marusik \& Koponen considered Acanthinozodium unavailable because no type species was designated at the first publication of the name. As a result, all species regarded as congeneric with Acanthinozodium were transferred to Zodariellum Andreeva \& Tyshchenko, 1968 (Platnick 2002, see also the World Spider Catalog 2015). We here use "Tyshchenko" spelled as in this late author's most recent publications (see Marusik \& Koponen 2001).

However, before the intended type species A. spinulosum was described by Denis, 1966, no other authors used the name, but Denis published three other papers with Acanthinozodium before that year (Denis 1952, 1956 and 1959). The first one contained two species and one subspecies of the genus, the second only one: A. sericeum Denis, 1956, the third one three. The case is complicated because, if Denis

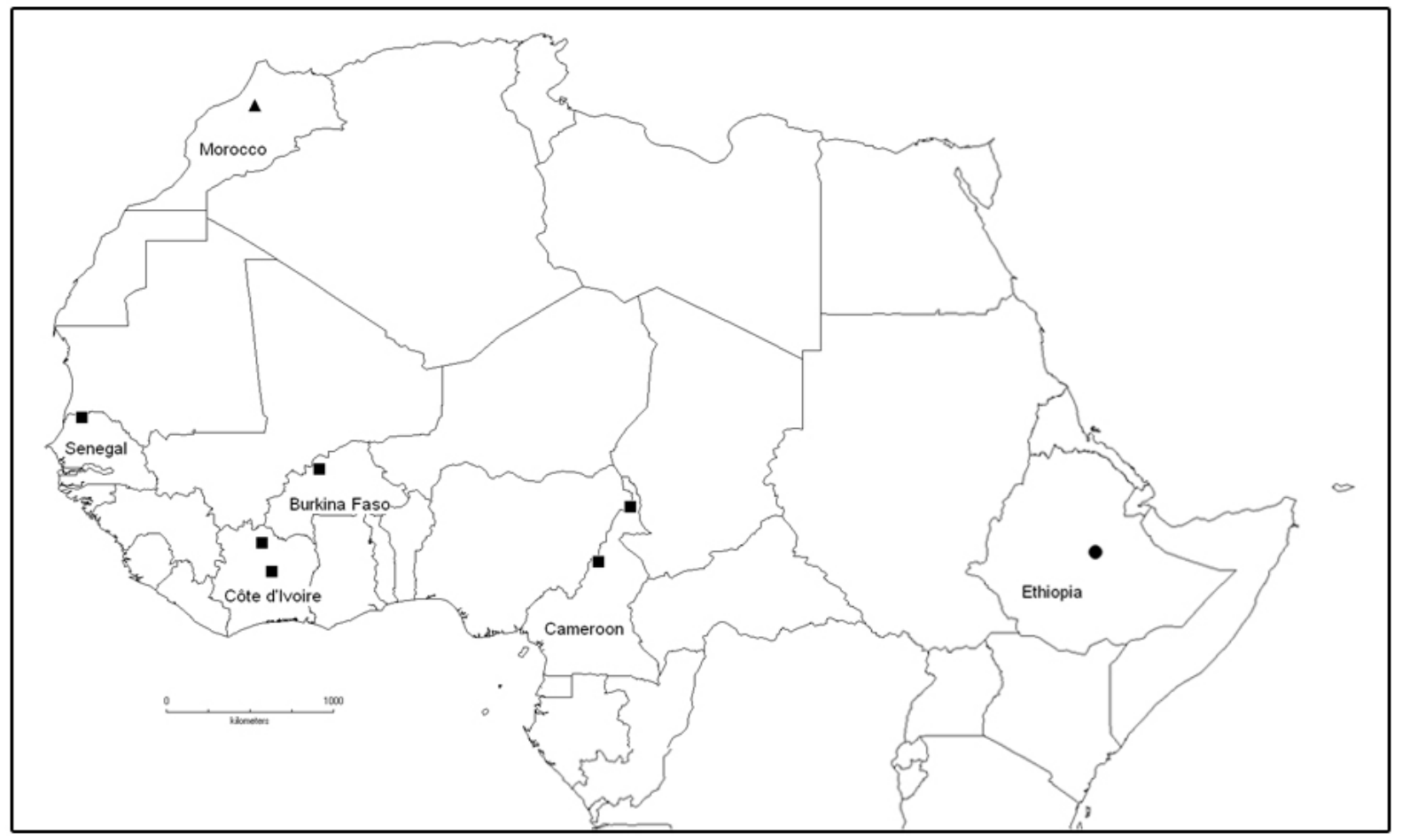

Fig. 13. Distribution map of A. crateriferum sp. nov. (•), A. sahelense sp. nov. (•) and A. quercicola sp. nov. $(\boldsymbol{\Lambda})$. 
(1956) had used a reference to the new genus in 1956, A. sericeum would have been the type species by monotypy and combined description. But he did so in the 1966 publication in which the description of the intended type species $A$. spinulosum was finally published. By that action Acanthinozodium becomes available and valid, and its type species is $A$. spinulosum Denis, 1966. This is confirmed in the catalogue by Brignoli (1983) who also stipulated that the 1966 paper of Denis makes the name available.

The vast majority of the comments (in litteris) about this case agree that Acanthinozodium is a valid genus. However, there is no complete unanimity as to whether the type species should be the first species described by Denis in 1952 (A. cirrisulcatum), as argued by Jocqué (1991), or the species Denis selected and confirmed as his choice in 1966 (A. spinulosum). The main argument to prioritize the former is that the selection of $A$. spinulosum would jeopardize the stability of the name Acanthinozodium. Since the name was not used by any other author before 1966 and possible synonyms were only created thereafter, we regard this argument as invalid. A second argument is "priority", but rules in this connection only concern synonymies. We therefore consider $A$. spinulosum the type species with the following rationale:

As no type species was proposed in 1952, the genus name is not available from Denis, 1952, according to the International Code of Zooological Nomenclature (International Commission on Zoological Nomenclature 1999, Article 13.3). The first time a type species was proposed-in 1966 -Denis designated A. spinulosum as the type species. Assuming that Denis included a statement that would satisfy Article 13.1 (ICZN 1999), then the correct name is Acanthinozodium Denis, 1966. There is no requirement for Denis to have nominated one of the originally included species as the type species. Also, Article 11.9.3.1 guarantees that any species described in Acanthinozodium prior to 1966 is validly formed, despite the genus-group name being not available until Denis (1966).

A further complication of this case is the synonymy with Zodariellum that was established by Jocqué (1991). The paper by Andreeva \& Tyshchenko (1968), in which the latter genus was described, is troubling as it contains several inconsistencies (see also Marusik \& Koponen 2001). The authorship of the type species of Zodariellum changes from Tyshchenko in the text to Andreeva \& Tyshchenko in the abstract. The heading of the new genus is "Lodariellum" instead of Zodariellum. These mistakes have little bearing on the use of the new genus name and its possible synonymy with Acanthinozodium, but the following has. Zodarion continentalis (Andreeva \& Tyschchenko, 1968)(which should be "continentale") was mentioned in the English abstract as belonging to "the three new Zodarion" (there mentioned as "Zodarium") species in the paper but described in between the Zodarion species as Zodariellum in the text, although the single illustration for that species (fig. 5) is attributed to "Z. continentalis" among the other Zodarion species.

The core of the paper, the particular characters of the type species of Zodariellum, its unusual small AME (fig.7 in Andreeva \& Tyshchenko 1968), the size and position of the eyes in the posterior row and the flat carapace, apparently escaped the attention both of Jocqué (1991) and Marusik \& Koponen (2001). The confusion in the Russian (Cyrillic) paper and the very superficial description of the genus with only a lateral view of the habitus and a dorsal view of the male palpal tibia, may explain these mistakes. Acanthinozodium can indeed not be a synonym of Zodariellum because one of the main characters of the former is exactly the large size of the AME, but also the profile of the carapace is different. Marusik \& Koponen (2001) based the attribution of their new species from Mongolia to Zodariellum on the similarity of the male palps with that in the crucial fig. 5 of Andreeva \& Tyshchenko (1968), which, in their description, was erroneously mentioned as belonging to "Zodariellum" continentalis.

The outcome of this discussion is as follows. Apart from those described in the present paper, Acanthinozodium now contains the following species: A. cirrisulcatum Denis, 1952, A. sahariense Denis, 1959*, A. sericeum Denis, 1956*, A. spinulosum Denis, 1966, A. subclavatum Denis, 1952, 
A. tibesti Jocqué, 1991* and A. zavattarii (Caporiacco, 1941)*. Only specimens of the species marked with * have been examined by the present authors. The genus Zodariellum now only contains its type species (Z. surprisum Andreeva \& Tyschchenko, 1968), as it is apparently the only species in the femoral organs clade with AME that have the same size as the other eyes. Other species that have been placed there, need to be transferred to Zodarion. However, it is worth to note that at least some species of the latter genus, i.e. species of the $Z$. thoni group appear to have small AME, the diagnostic character of Zodariellum. These observations show a need for revisions of these very diverse groups.

\section{The cymbial pit}

Species of Acanthinozodium have a conspicuous circular pit at the base of the cymbium. This hole is not always easily observed as it is sometimes filled with a colourless gel-like substance. However, when it is empty, it appears as a large crater-like depression with a ringed inner wall (Figs 9A-B, 10C, 12B-D). The most plausible hypothesis so far is that it represents the outlet of a gland that produces a sticky matter used to seal the epigyne after copulation. The surface of the amorphous matter in the pit is irregular and sometimes has long thin smears (Jocqué \& Harten, in preparation), just like glue that has been pressed out of a tube. Epigynes of Acanthinozodium have large atria that are often filled with a large sticky plug that protrudes above the surrounding tegument (Figs 1A, 5H, 12A). Epigyne plugs are not uncommon in spiders (Uhl et al. 2010). The most commonly mentioned plugs are parts of the palp, more precisely of the embolus. The consequence of this plugging system is that males, leaving the emboli behind as plugs (Fromhage \& Schneider 2006), loose the possibility to mate another time. In other species, male spiders produce a sticky matter that is meant to be applied to the epigyne either to impede subsequent matings by other males or to prevent backflow of sperm, but remain polygamous themselves. There are apparently several types of sticky plugs: glands that produce a sticky matter within the male palp, released through a separate opening at the base of the embolus base as in some Amaurobius C.L. Koch, 1837 species (Suhm et al. 1996) or ejected through the embolus itself. In the latter case the plug has to be produced and introduced into the epigyne copulatory tract after sperm transfer (Uhl et al. 2014). This type of glands was well documented by Uhl et al. (2014) for Oedothorax retusus (Westring, 1851). Its efficiency is fairly high (Kunz et al. 2014), but depends on the size and the time it takes to harden. Since the canal through which the matter is ejected is very narrow, it is not surprising that the amount of sticky matter that can be transferred is restricted and should also have a low viscosity. These prerequisites are presumably less stringent in the second type of sticky plugs that are produced by a gland that ejects the matter through a wide canal in the cymbium. Such glands are supposed to be present in Storenomorphinae (Jocqué 1991, figs 39-40) where the cymbium is provided with hollow setae and epigynes are very often completely covered by a rubbery matter. The Acanthinozodium crater-like plug-pit can also be assumed to be an efficient outlet for sufficient viscous sticky matter to block the large atria of the epigyne (Figs 5H, 12A).

\section{Acknowledgements}

We are indebted to Mark Harvey, Norman Platnick, Thomas Pape, Stephen Thorpe and Laurent Raty for their interesting and useful comments in connection with the nomenclatural problem presented here. We thank Alain Reygel for the drawings and Robert Bosmans and Sylvain Déjean for the loan of specimens. We are grateful to Gabriele Uhl for critical comments on the plug-pit hypothesis. This paper is publication BRC 325 of the Biodiversity Research Center (Universite Catholique de Louvain). This publication is financed thanks to the FRIA (Fonds pour la Formation à la Recherche dans l'Industrie et dans l'Agriculture).

\section{References}

Andreeva E.M. \& Tyschchenko V.P. 1968. Materials on the fauna of spiders (Aranei) of Tadjikistan. II. Zodariidae. Zoologicheskii Zhurnal 47: 684-689. 
Brignoli P.M. 1983. A catalogue of the Araneae described between 1940 and 1981. Manchester University Press, Manchester.

Denis J. 1952. Zodariides recueillis au Maroc et en Mauritanie par M. L. Berland. Bulletin de la Société d'Histoire naturelle d'Afrique du Nord 41: 58-63.

Denis J. 1956. Notes d'aranéologie marocaine.-VI. Bibliographie des araignées du Maroc et addition d'espèces nouvelles. Bulletin de la Société des Sciences naturelles du Maroc 35: 179-207.

Denis J. 1959. Description de deux Zodariides (Aranéides) nouveaux du Sahara. Bulletin du Muséum national d'Histoire naturelle 31 (3): 238-241.

Denis J. 1966. Les araignées du Fezzân. Bulletin de la Société d'Histoire Naturelle de l'Afrique du Nord 55: $103-144$.

Fromhage L. \& Schneider J.M. 2006. Emasculation to plug up females: the significance of pedipalp damage in Nephila fenestrata. Behavioral Ecology 17 (3): 353-357. http://dx.doi.org/10.1093/beheco/ $\underline{\operatorname{arj} 037}$

International Commission on Zoological Nomenclature 1999. International Code of Zoological Nomenclature. $4^{\text {th }}$ Edition. International Trust for Zoological Nomenclature, London.

Jocqué R. 1991. A generic revision of the spider family Zodariidae (Araneae). Bulletin of the American Museum of Natural History 201, American Museum of Natural History, New York.

Levy G. 1992. The spider genera Palaestina, Trygetus, Zodarion and Ranops (Araneae, Zodariidae) in Israel with annotations on species of the Middle East. Israel Journal of Zoology 38 (2): 67-110.

Marusik Y.M. \& Koponen S. 2001. Spiders of the family Zodariidae from Mongolia (Arachnida: Araneae). Reichenbachia 34: 39-48.

Kunz K., Witthuhn M. \& Uhl G. 2014. Do the size and age of mating plugs alter their efficacy in protecting paternity? Behavioral Ecology and Sociobiology 68 (8): 1321-1328 http://dx.doi.org/10.1007/s00265$\underline{014-1742-7}$

Ono H. \& Jocqué R. 1986. Two new species of the family Zodariidae from Saudi Arabia (Arachnida: Araneae). Fauna Saudi Arabia 8: 6-11.

Platnick N.I. 2002. The world spider catalog, version 2.5. American Museum of Natural History [online]. Available from http://research.amnh.org/entomology/spiders/catalog81-87/index.html [accessed 15 Dec. 2014]

Ramírez M.J., Grismado C.J., Labarque F.M., Izquierdo M.A., Ledford J. M., Miller J.A., Haddad C.R., Griswold C.E. 2014. The morphology and relationships of the walking mud spiders of the genus Cryptothele (Araneae: Zodariidae). Zoologischer Anzeiger 253 (5):382-393. http://dx.doi.org/10.1016/j. jcz.2014.03.002

Suhm M., Thaler K \& Alberti G. 1996. Glands in the male palpal organ and the origin of the mating plug in Amaurobius species (Araneae: Amaurobiidae). Zoologischer Anzeiger 234 (3):191-199.

Uhl G., Nessler S.H. \& Schneider J.M. 2010. Securing paternity in spiders? A review on occurrence and effects of mating plugs and male genital mutilation. Genetica 138 (1): 75-104. $\underline{\text { http://dx.doi.org/10.1007/ }}$ $\underline{\text { s10709-009-9388-5 }}$

Uhl G., Kunz K., Vöcking O. \& Lipke E. 2014. A spider mating plug: origin and constraints of production. Biological Journal of the Linnean Society 113 (2): 345-354. http://dx.doi.org/10.1111/bij.12359

World Spider Catalog 2015. World Spider Catalog, version 16. Natural History Museum Bern. Available from http://wsc.nmbe.ch [accessed 27 Jan. 2015] 
JOCQUÉ R. \& HENRARD A., Revalidation and new species of Acanthinozodium (Araneae, Zodariidae)

Manuscript received: 8 November 2014

Manuscript accepted: 29 December 2014

Published on: 4 March 2015

Topic editor: Koen Martens

Desk editor: Charlotte Thionois

Printed versions of all papers are also deposited in the libraries of the institutes that are members of the EJT consortium: Muséum national d'Histoire naturelle, Paris, France; Botanic Garden Meise, Belgium; Royal Museum for Central Africa, Tervuren, Belgium; Natural History Museum, London, United Kingdom; Royal Belgian Institute of Natural Sciences, Brussels, Belgium; Natural History Museum of Denmark, Copenhagen, Denmark. 